\title{
The Experience and Practice of Social Support during Major Organizational Changes: The Case of the Bank Collapse in Iceland in 2008
}

\author{
Ásta Snorradóttir ${ }^{1,2}$, Guðbjörg Linda Rafnsdóttir ${ }^{1}$ \& Birgit Aust ${ }^{3}$ \\ ${ }^{1}$ The University of Iceland, Faculty of Social and Human Sciences, Reykjavík, Iceland \\ ${ }^{2}$ Administration of Occupational Safety and Health, Reykjavík, Iceland \\ ${ }^{3}$ National Research Center for The Working Environment, Copenhagen, Denmark \\ Correspondence: Ásta Snorradóttir, Administration of Occupational Safety and Health, Reykjavík, 110, Iceland. \\ Tel: 354-862-1602. E-mail: asta@ver.is
}

Received: March 15, 2016

Accepted: April 14, 2016

Online Published: June 18, 2016

doi:10.5539/ijbm.v11n7p12

URL: http://dx.doi.org/10.5539/ijbm.v11n7p12

\begin{abstract}
This study explored how Icelandic bank employees perceived and practiced social support in the wake of the economic crisis when the banks suddenly collapsed in 2008. Drawing on 20 interviews with bank employees, it was found that during stressful situations, employees referred to social support as one of the most important factors in overcoming the changes. The study points toward a complex picture of social support practices during organizational changes and underlines the importance of distinguishing between both nature and source of the social support in practice and in research.
\end{abstract}

Keywords: leadership, social support, organizational changes, downsizing, well-being

\section{Introduction}

Over the past few decades, deindustrialization, the free market economy, globalization, and economic crisis have changed the labor market dramatically, where it has shifted toward a more precarious work environment in most industrialized countries. These changes have been manifested at the organizational level in frequent incidences of major change, such as organizational downsizing and restructuring (Ferrie, Westerlund, Virtanen, Vahtera, \& Kivimki, 2008). In a review of 86 international studies on the relationship between organizational changes and the health and well-being of employees, Quinlan and Bohle (2009) found that $85 \%$ of the studies reported negative consequences for employees' health and well-being. Studies have shown that the most likely cause of negative changes to health stem from changes in the psychosocial work environment, especially if these lead to increased demands, decreased job control, decreased social support, and high job insecurity (Kivimaki, Vahtera, Pentti, \& Ferrie, 2000; Vahtera, Kivimäki, Pentti, \& Theorell, 2000).

This paper contributes to this field of research with a qualitative study on how Icelandic bank employees perceived and practiced social support during major organizational changes in the wake of the financial crisis of 2008. At this time, bank employees experienced rapid and unpredicted organizational change when the three biggest Icelandic international banks - comprising $85 \%$ of the nation's banking system — collapsed within a period of 10 days. The authors are not aware of other examples of studies on such sudden changes within a whole occupational setting in a nation. When the banks collapsed, they were saved by the government, but were reduced to public domestic banks instead of maintaining their status as private international organizations. For the approximately 3000 bank employees, this meant that their workplaces changed dramatically overnight. About $20 \%$ of the employees were laid off and the banks were restructured. The bank collapse had an immense impact on Icelandic society and represented a major threat to the nation's economy. Right after the collapse, the country entered a deep economic recession. Many businesses went bankrupt because of the unstable economy and unemployment rose steeply. In addition, many individuals faced financial insecurity as loans escalated and savings in the banks were lost (Matthíasson, 2008). The Icelandic nation was in anguish, protests were widespread, and general trust in the pillars of society dropped (Thórisdóttir \& Karólínudóttir, 2014). 
This study draws on previous quantitative studies concerning the health and well-being of the bank employees following the collapse. In the study by (Snorradóttir, Tómasson, Vilhjálmsson, \& Rafnsdóttir, 2015), where the health and well-being of the Icelandic bank employees was observed 6 months after the bank collapse, it was found that the employees who kept their jobs at the banks fared worse for all outcomes of health and well-being studied than those who were laid off in the early aftermath of downsizing. Furthermore, Snorradóttir, Vilhjálmsson, Rafnsdóttir, and Tómasson (2013), found that employees who were more entangled in the change process experienced more psychological distress than other employees who remained working in the banks following the collapse. In that study, job control and empowering leadership reduced psychological distress among the employees. Surprisingly, support from neither co-workers nor supervisors reduced psychological distress further. Because of this, it was speculated that social relationships which were important for social support might have been harmed due to the layoffs of colleagues. In terms of supervisors' support, it was also speculated that there might be an overlap between empowering leadership and support from supervisors.

To better understand employees' experience working in the collapsed banks, we conducted interviews with 20 bank employees who had been working in the banks during and following the bank collapse. In this qualitative study, we investigate the role of social support among the bank employees a. The focus is on how social support was experienced and practiced within the workplace during the changes, which might shed new light on the previous findings by Snorradóttir et al. (2013) on the role of social support among the bank employees following the collapse. This qualitative study aims to better understand the characteristics of the supportive relationships at work, the meaning of support for employees, how it is practiced and if there are different forms of social support within a changing work environment. This is in line with McGuire (2007), who pointed out that studies on social support have relied mainly on survey data, while qualitative studies incorporating employees' views on social support at work are lacking. Before explaining the details of the study, some important aspects of social support are appraised that will be drawn upon in the analysis and discussion of the qualitative interview data.

\section{Literature Review}

\subsection{Different Sources and Types of Social Support}

Theories on the importance of good social relationships for well-being were first developed a long time ago. Emile Durkheim was one of the first to raise the idea that one of the key elements for individuals' well-being is their social relationships, representing social cohesion and the individuals' social integration into the society (Durkheim, 1972 [1893]). Durkheim (1893/1972) defined social cohesion as connectedness and solidarity in a social group. More recent studies have found that social support-where individuals give and receive both emotional and instrumental support-thrives better in a social environment where social cohesion exists (Campbell \& Pepper, 2006; House, 1981). In such an atmosphere, positive membership is produced and maintained and through cohesiveness; group members achieve consensus and encourage a positive view of the group as a social unit, allowing them to resolve disagreements and work toward increasing positive and reducing negative relationships (Friedkin, 2004).

McGuire (2007) argued that even though social support has been widely studied, there seems to be no consensus on the actual meaning of this term. He stated that within the literature, many items that supposedly constitute social support have been used to measure it, but this has not led to an actual understanding of the concept. For instance, the exact characteristics of social support relationships or the norms underlying the provision of social support have not been clarified. In a similar vein, in an earlier study, Uchino, Cacioppo, and Kiecolt-Glaser (1996) criticized research on social support for treating it as a unidimensional rather than a multidimensional construct. They pointed out that it is common to add various aspects of social support into one variable, where no distinction is made between different sources or types of these elements. In contrast to the trend in previous work, it is important to observe the different sources and nature of social support, as they can have different effects depending on what the support is needed for (Uchino et al., 1996).

In the early 1980s, House (1981) already suggested distinguishing between different types of social support, namely emotional support, as expressed in empathy or active listening, and instrumental support, as expressed in provision of actual help. In terms of different sources of social support within the work environment, a distinction is typically made between support from managers or supervisors and support from co-workers. Co-worker support is thought to be expressed in assisting with work tasks (House, 1981), or it can take the form of non-intimate or intimate relations where sharing of both work-related and non-work-related matters can be combined (McGuire, 2007). Supervisor support is considered to be more consistent and available when it comes to giving information, suggestions, listening to concerns and complaints. Supervisor support is also thought to 
provide solutions, as supervisors have access to resources (power) whereas co-workers do not (Ng \& Sorensen, 2008).

\subsection{Organizational Changes and Social Support}

Research on organizational changes and social support is often quantitative and focuses on a lack of social support. Such quantitative studies have shown mixed results regarding health outcomes. Some have demonstrated that employees with low levels of social support are at increased risk for worse health and well-being during the changes (Niedhammer, Chastang, David, Barouhiel, \& Barrandon, 2006; Petterson, Hertting, Hagberg, \& Theorell, 2005; Vahtera et al., 2000). Other studies have demonstrated no effect of low social support during organizational changes on health and well-being outcomes (Lavoie-Tremblay et al., 2010). In a longitudinal study on downsizing in organizations. Vahtera et al. (2000) observed the effect of both improved and lowered levels of social support prior to any downsizing and following downsizing. They found that lowered levels of social support from co-workers and supervisors related to lower health, whereas improved social support from supervisors was able to reduce the negative effects of other psychosocial factors, such as low or decreased job control, on the health and well-being of employees.

Qualitative studies on social support and organizational change have mostly focused on how social relations are disrupted during the change process. Campbell and Pepper (2006), for instance, showed that during a major downsizing at a large energy plant in the United States, many social networks were lost, resulting in little or no social cohesion. In addition, Koebers' (2002) research on a technological company in the United States showed how job insecurity resulted in disrupted social relations, marked with suspicion as employees evaluated who deserved to be laid off. In line with this, Shah (2000) found that social networks were harmed in a company where major downsizing took place, as employees lost co-workers who had been an important source of support. This also contributed to feelings of being less integrated within the workplace.

\subsection{The Different Contributions of Support from Supervisors and Support from Co-Workers}

Studies have shown that during major organizational changes, the role of management can be very important. Managers and supervisors can make a real difference in the outcome for the psychosocial work environment and hence the health and well-being of employees. Stensaker and Langley (2010) argued that the role of supervisors is crucial during organizational changes, as they navigate a path between the demands of the top management to implement changes and their own conceptions of what is required to maintain productivity and keep employees content. Others have found that when supervisors, for instance, encourage decision making during changes and are active in informing employees, stress among employees can be reduced (Arnetz, 2005; Svensen, Neset, \& Eriksen, 2007). During organizational changes, the distinction between co-worker and supervisor support may therefore be highly relevant. Vahtera et al. (2000) showed that good supervisor support was more important than good co-worker support. Further, Hertting, Nilsson, Theorell, and Larsson (2004) found that employees' job strain increased when managers failed to understand how the changes affected employees and their work; this led to employee frustration and lack of trust in management.

This review shows that study findings have been contradictory regarding the role of social support during major organizational changes. This study aims to understand the experience and practice of social support among bank employees going through organizational changes during economic recession.

\section{Methods}

Semi-structured in-depth interviews were conducted from January 2013 to May 2013 with 20 bank employees who were employed in one of the three Icelandic banks before, during, and after the collapse of the institutions. Participation in the study was based on employees' volunteering to report on their experiences during the time of the organizational changes. Participation was open to both women and men of all ages and of all different job groups from both the branches and the headquarters. Bank employees were contacted through emails sent out by either the Confederation of Icelandic Bank and Finance Employees, the main union for bank employees in Iceland $^{1}$, or by the human resource departments within the banks. To assure anonymity, the email detailed that those willing to participate should contact the first author directly and that no information about the participation in the study would be given to the employer. For practical reasons, the interviews were conducted with those respondents who lived in or within a few hours' drive of the capital area. This recruitment strategy resulted in 13 female and 7 male participants. The uneven number of male and female participants reflects that the majority of bank employees are women, especially as very few men work as front-line service workers in the branches. When the last interview was conducted, we determined that no new knowledge had been added and therefore concluded that saturation had been met. 
All interviews were conducted by the same researcher. It was up to the interviewees to choose where the interview should take place. Most participants (14) chose to talk with the researcher in a meeting room at their own workplace. Four participants came to the researcher's office and two invited the researcher to conduct the interview in their home. It was not observed that the location made any difference to the quality or content of the interviews. The interviews lasted between 45 and 90 minutes. They were semi-structured and focused on the participants' experiences regarding their psychosocial work environment during the time when the banks collapsed and what they experienced as the most important factor in their work environment that helped them during this difficult time.

Thematic analysis approach was applied to analyze the data (Braun \& Clarke, 2013). It addresses the data by identifying, analyzing, and reporting patterns (themes). This approach was chosen as it seemed to fit best to our explorative and inductive investigation. All interviews were transcribed verbatim and coded using Atlas.ti. Initially, the data were read through in detail in order to identify initial codes. In the next step, the focus was on codes dealing with different aspects of social support and grouping them in initial themes. The themes were then further reviewed and defined. Finally, some themes were collapsed into a broader theme and named.

The participants were not asked about their exact age, but their age ranged from around 30 to being in their 60s. An equal number worked in the branches and at the headquarters. Participants came from a mixture of job groups, including cashiers, supervisors, customer service representatives, and specialists in various departments. To maintain the employees' anonymity, detailed descriptions of participants will not be given when citing parts of the interviews. Iceland has less than 350000 inhabitants and giving out such detailed information could jeopardize their anonymity. Therefore, when quoting from the interviews, we will only state whether participants are male or female and work at a branch or at the headquarters, as the jobs in these two settings can differ, that is, most employees in the branches are front-line service workers, but in the headquarters they work as specialists on different aspects of the banking operations.

\section{Findings}

Through the analysis of the interviews, the following four themes were identified: 1) abrupt changes and increased social cohesion, 2) organized social support, 3) available emotional support, and 4) the role of supervisors in social support. These will be presented in detail below.

\subsection{Abrupt Changes and Increased Social Cohesion}

The bank employees generally referred to the collapse of the banks as unexpected and unforeseen. Many talked about how unprepared they were for the situation. Although it had seemed clear for some time that there was some turbulence in the international financial markets, it was common for the interviewees to say that the bank management at each of the banks had reassured the employees that their bank was safe even if other banks might be at risk. Interviewees reported how, even the day before their bank collapsed, top managers assured them that there were no signs of a major crisis in the financial sector. The following quotation is similar to many employees' evaluation of the situation:

I have often recalled that in this month before the crash I heard a lot of people saying the banks were going bankrupt and I was just so clueless or whatever and I was not in this circle of the tops who really knew what was going on, one just never imagined and just thought that all was good and I once said to someone that it is just as likely that the banks would go bankrupt as an elephant would walk into my office. But the elephant never walked into the office, but the bank went bankrupt. See, I was totally surprised, I just did not expect this. (Male branch employee)

Following the collapse, many experienced a chaotic atmosphere laden with uncertainty. Layoffs and restructuring started soon after the collapse and almost all interviewees mentioned feeling insecure about the future of their job. In addition, some talked about how difficult it was to witness their co-workers being laid off, while others reflect on the uncertainty about the future of the banks operation, as information was lacking. When reflecting on the events, bank employees often described what they experienced as a shock or even a trauma. In their descriptions, interviewees used terms such as "natural disaster," "catastrophe," or "hurricane" to describe the time when the banks collapsed. Some counted this experience as a serious trauma in their lives and compared it to other severe life experiences.

In most of the interviews, the bank employees explained that in this atmosphere of chaos and uncertainty, employees developed a greater sense of consensus, in the sense of looking out for each other and taking care of one another. Being a part of a cohesive group of co-workers was referred to as the most important factor in the 
immediate aftermath in dealing with the shock and misery accompanying the collapse. This was illustrated in the words of one female employee working at the headquarters:

[Following the collapse] people simply needed to survive and everyone looked out for everyone, you know, without thinking just about yourself ... Before the collapse this was just a good group ... this consensus was formed after the collapse, in the group that remained.

The interviewees reported that it was not only chaos and uncertainty which contributed to this cohesiveness. The fact that the collapse of the banks had also wide social consequences left many of the bank employees with the feeling that they were being blamed for the nation's economic and social crisis because they were employed in the Icelandic banks. Many felt that the wrath of society that focused on the banks was also directed at them personally. A female interviewee working in a branch described how bank employees were being accused in public and how she avoided confrontation:

I noticed that people would just let loose on us out in the supermarket, you know, like we were some kind of criminals who worked at such companies. We had not done anything wrong. This was really difficult and a bad experience and of course I can assure you that I did not tell anyone first hand that I worked in a bank for a long time. I just didn't feel like taking up that discussion.

There were similar reports from many of the other interviewees. They reported hiding from the public and avoiding social gatherings - even among friends and family — as they expected to be questioned about their employment in a bank or feared having to listen to negative judgments about their workplaces. As a consequence, employees started to rely more on each other, as expressed by a male employee at one of the headquarters:

We [bank employees] started to hang out together more frequently after work, because we felt like it ... we felt we had more in common with each other these first weeks after the collapse than with someone else.

The perception of being blamed for the negative social and economic changes also gave them the impression that they had to set aside their personal experiences of the crisis. Being employed in the banks made it impossible for them to react in the same way as other Icelanders; they did not perceive that they could show or share their frustration with their countrymen or protest as other Icelanders were doing, as that meant protesting the banks and hence themselves. In that sense, some interviewees expressed that it was important to be close to their co-workers and share the experience with them, as others could not comprehend what they were going through. A female interviewee from one branch described her perception that only co-workers could understand the particular situation of bank employees after the collapse:

You wouldn't want to burden just anybody with this [the experience of working in a bank during the collapse], people who don't know what you're talking about.

Interestingly, the experience of finding relief in a cohesive group of co-workers only seemed to apply to employees where they had already known their co-workers for a while. A female branch interviewee felt that she was alone and without support when she was transferred to a new department, because she did not know her new co-workers. Furthermore, it seems that where working climate was poor before the collapse, these organizational changes could result in a less supportive atmosphere, as one branch interviewee explained. She perceived that the morale was weak prior to the collapse, and the changes in the bank resulted in less communication within the group as a result of an increased workload and a simultaneous reduction in the number of employees in the group:

It seems everyone was just relieved to get out and go home, there is very little consensus, the group isn't as tight, of course we are fewer and it seems like everyone has just had enough.

In this case, the collapse of the banks did not lead to increased cohesiveness but rather the opposite, namely increased detachment among co-workers.

\subsection{Organized Social Support}

The tension and irritation that was evident among the general public was also directly experienced in the branches when serving customers who had lost their savings or saw their loans escalate, as they turned their anger and frustration towards the employees. Many interviewees from the branches experienced this direct contact with customers as the most difficult work-related challenge that followed the collapse. Quite frequently, employees faced tense situations, which in some cases involved direct threats, as described by a female employee at one of the branches: 
But this was a terrible time, we felt really bad and we were half afraid that we could be physically attacked, well, you were kind of insecure.

Branch employees who report a more successful process of overcoming of these situations described how social support-including both emotional and instrumental support - was systematically established as a core feature in dealing with these challenges. These interviewees described how supervisors in the branches took charge in establishing a supportive atmosphere and guiding the group members in how they could support one another.

Many branch employees described a variety of forums organized by the supervisor to discuss difficulties encountered throughout the day. These could be staff meetings, where supervisors established a venue to relieve stress and pressure at the end of the work day, or a staff meeting, prior to opening hours to prepare for the day. These forums had the important role of sharing experiences, such as talking about confrontations with customers and associated negative feelings. It also provided a way for them to support each other; as one female employee commented, "It was very helpful to sit down and talk about things that had happened ... we were completely supporting each other you know." The interviewees reported that these arrangements helped them to cope with stress and prevented employees from being affected by negative experiences with customers in their private lives. The different forums for exchange and support also provided some opportunities to learn what measures were actually helpful in serving difficult customers. One branch employee described finding out that it helped when a second employee stepped in to assist when a colleague in a difficult situation while serving a customer. That became a process applied in similar situations. There were also descriptions of how employees were prepared by supervisors to step in to assist when their co-workers were facing a high workload. In that way, they tried to distribute the strain equally.

Generally, those who had this kind of support expressed being content. However, organizing support and talking through the problems added time to the working day. A male interviewee described that he was ready to put in the extra work to achieve a supportive work environment:

[B] ut [giving support] cost sometimes because you take on some extra work and spend more time on your cases, or relenting a bit in your work. But I don't think this is anything to regret, it's worth it for the morale and other stuff in reaching this group support; we approach the projects and challenges together.

\subsection{Available Emotional Support}

Even if the employees in the headquarters were not in direct contact with potentially angry customers, they also expressed a need for support to deal with the changing work environment and accompanied changes in their work. This could involve an increased workload or the work becoming less challenging and more repetitive for some. Employees working in the headquarters often referred to having access to support from either their co-workers or their supervisors. Unlike in the branches, there were no descriptions the support being enhanced systematically in any way. In these cases, employees mostly referred to emotional support, which involved the availability of someone to talk to and share things with. Some referred to this as having a good friend at work. A few interviewees also stated that the most important factor in overcoming the organizational changes was the availability of this kind of emotional support from either co-workers or supervisors. As one female interviewee at one of the headquarters commented:

To have someone you can talk to and you trust, that is by far the most important thing ... and if your supervisor makes you feel good about ... I mean makes you feel that you make a difference.

Some interviewees were less formal in how they express the support available to them and refer to a good social atmosphere which was highly appreciated and created a more positive outlook on work, as reflected in the words of this female interviewee in one of the headquarters:

I don't wallow in whether I dread going to work. If you have good colleagues and the atmosphere is good, this makes up for all that.

Although many employees at the headquarters appreciated the emotional support they experienced at work, interviewees still reported having to carry out demanding or dull tasks. Many employees felt especially overwhelmed because their jobs demanding a lot of hours, projects were stacking up, and the pace of work was becoming too fast. For those, feelings of being emotionally supported by either their co-workers or supervisors did not suffice to reduce stress or prevent it from affecting their well-being. This was reflected in the words of one female employee, who had also expressed that she felt she had good access to emotional social support at work: 
We just worked and worked and worked, one just showed up at work and just worked, then came home after 10 or 12 hours and just into bed and to sleep and this is how it went on and on for a few months, just working and sleeping. It was crazy, just totally crazy.

When asked about her private life, she responded, "Nothing, I just had no energy left ... I just went home to sleep."

Two of the interviewees vividly described the availability of emotional support in their work environment and explained that they were eventually exhausted by the high workload and had to take a long leave of absence. However, the social support they experienced might have prevented even worse feelings of discontent. It also seems that the high level of social support within the group increased their loyalty to their workplace and influenced their decision about returning to work. Both of them returned eventually, although they both initially thought they would not do so. One of the interviewees talked about her decision to return after sick leave:

I think that if my colleagues [had left], it would have been much easier for me to make the decision [to quit] because you feel you have to do this with them and get through it with them.

\subsection{The Role of Supervisors in Social Support}

The role of the supervisors in leading employees through changes came out as a strong factor in the interviews. There were both positive and negative reports of how supervisors guided employees through the period after the collapse. What stands out is that, generally, those who were content with their supervisor also referred to a more supportive work environment during the changes. In contrast, those who were discontent with their supervisor referred to a work environment characterized by limited cohesion and social support. Employees who perceived that the period after the collapse was dealt with in a positive way described their supervisors as being visible, supportive, prepared to lead and take sides with employees, fair, and good listeners. Those who found that the period after the collapse was not managed well described their supervisors as being invisible, out of reach, not on site, and disrespectful. One employee mentioned that the organizational changes had demonstrated to him how important good managerial practices were. In his department, a new supervisor came in during the changes; this showed him what a difference a good supervisor could make:

Before the collapse we had difficulties with the morale, personnel changes were frequent ... but when my supervisor was replaced, things started to improve, communications improved, we were all on the same level ... I think the supervisor works systematically towards having things that way, which I appreciated very much during such difficult times.

As shown, supervisors played an important role in the organized support system for tackling customer abuse. A lack of supervisor support in such a setting was described by a few interviewees. One commented on the failure of instructions issued by the supervisor concerning how employees should support each other. She explained that the manager did not give guidance related to how that support should be activated. In practice, she experienced that within the work group, a request for support created more stress, as everyone was already very busy. Therefore, employees stopped asking each other for support.

Another interviewee working in a branch reported that although employees organized support without the help of their supervisor, both by helping out in difficult situations and comforting each other, the situation was so intense and the problems so difficult to handle that such support did not suffice. One interviewee reported that a number of employees from this branch went on long-term sickness absence due to exhaustion. According to the employee reporting about this, the lack of management was the main reason for the bad outcome. As she stated:

We experienced a lot of injustice and felt somehow like management disappeared and that we [the branch employees] had to take everything on ... we faced a lot of pressure, and it was like management wasn't there.

\section{Discussion}

The aim of this article was to explore the role of social support and the ways it was practiced and experienced by Icelandic bank employees during major organizational changes taking place following the collapse of the banks in 2008. The aim of this qualitative study, was to shed further light on the issue of social support as major organizational changes occurred, and in particular, to better understand which aspects of social support and its practices are experienced as helpful in enhancing well-being during such changes.

It was found that social support can be a core feature in overcoming the challenges that arise during major organizational changes. The findings showed that within the banks, various supportive activities were experienced and practiced. In this particular case of major organizational changes, it was found that employees 
were dealing with both abrupt organizational changes and related changes with their job tasks; many employees were also burdened with the negativity that was directed to the banks and themselves as bank employees. The negativity the employees experienced was a new stressor for them and was especially experienced by employees in branches, who were in direct contact with customers. The interviews suggested that this new stressor from the outside contributed to the increased social cohesion found among bank employees following the collapse. In addition, it was found that in some of the branches, this problem was approached with enhanced social support organized by supervisors.

Some of the supervisors established a support system that involved both emotional and instrumental support tailored to meet employees' needs and help them overcome the difficulties. This kind of support was described as structured in practice; it involved venues for giving out and receiving emotional support and a structured pathway for how to practice instrumental support in dealing with the tasks at hand. The repeated meetings, for instance, were a forum to share feelings and difficult experiences, as well as to exchange information and solutions on how to best tackle the stressful situation. The findings indicated that when taking this approach to social support during these difficult times, employees found it successful in resolving the stressors at hand.

The social support that was experienced or practiced among employees at the headquarters mainly involved emotional support. Here, employees were not dealing with difficult customers, but they still faced increased workloads as job tasks piled up or the job became more repetitive. There are no indications in those cases that social support was structured around the stressors at hand. Among these employees, social support was described as a good social atmosphere or feeling like having a friend at work. The employees perceived that support from co-workers or supervisors were available to them when needed. The emotional support, however, did not compensate for the lack of instrumental support; employees still became exhausted from having to deal with a new situation regarding their work tasks. Even so, emotional support was experienced as important, as it helped the interviewees to cope with some of the negative aspects of their new work situation. For some, social support at work contributed to the decision to return to the workplace following long-term sick leave due to exhaustion.

Emotional support is very important and may add personal touch to the work and reduce negative feelings, as McGuire (2007) has shown. He found that emotional support at work can involve such active support as counseling and caretaking, and work-related relationships can be so personal and intimate that they sometimes resemble close family ties. This seemed to have been the case for the bank employees. Therefore, employees benefitted from the emotional support, even though they lacked more instrumental support.

The findings can be viewed in line with Uchino et al. (1996) who emphasized applying the appropriate support for the stressor at hand. In the case where social support was systematically structured, it seems to have involved regular assessment of stressors and a flexible approach to solutions so that the support could be enhanced to meet the needs of the employees. In contrast, where emotional support was mainly described as being available, it did not involve this regular assessment of the need for support to meet the stressors at hand. The use of these two different approaches can probably be related to the stress involved in facing the anger and dissatisfaction from the difficult customers in the branches, which represented a new stressor. This could have called for new approaches to meet the stressor with novel solutions. The changes in the work tasks could have been regarded as a stressor that was dealt with on a regular basis, so that new approaches involving social support were not required.

In the previous quantitative research by Snorradóttir et al. (2013), they found that in the early aftermath of the bank collapse, empowering management was a stronger predictor than social support in reducing psychological distress. In that study, they considered the possibility that social relations important for support had been lost during the downsizing in the banks. In contrast, the present study showed that employees felt that social cohesion increased following the collapse and employees had access to various forms of social support, which they found to be among the most important elements in overcoming the stress that arose during the organizational changes. At first glance, these two findings seem to be contradictory. However, as pointed out in the introduction, Snorradóttir et al. (2013) also speculated whether empowering management could be perceived as some sort of supervisor support. In the present research, evidence is found in favor of this assumption. When supervisors made efforts in their tasks of leading employees through the difficult times, by either coming up with solutions or being available to assist employees in any way, employees were more likely to feel supported and to experience a good social atmosphere. It can therefore be argued that the empowering management was actually a form of supervisor support. With this in mind, the previous finding of Snorradóttir et al. (2013) might be seen in a new light. Both the quantitative and the qualitative study point towards similar results, namely that it is highly important for the well-being of employees for supervisors to lead in enhancing a supportive atmosphere during 
organizational changes. This is in line with what others have pointed out about the role of supervisors in such changes (Arnetz, 2005; Stensaker \& Langley, 2010; Svensen et al., 2007).

Supervisor support has also been found to be more important than co-worker support during organizational changes (Vahtera et al., 2000). This was also found in the present study: When employees initiated supportive practices during stressful situations without the supervisors; support, they found that they lacked resources to solve the problems. This is in line with $\mathrm{Ng}$ and Sorensen (2008), who pointed out that supervisor support differs from co-worker support in that supervisors have the power, therefore supervisors can make changes to the psychosocial work environment, enabling positive factors such as social support to thrive.

This qualitative study showed the importance of exploring the multidimensional nature of social support, as pointed out by Uchino et al. (1996). In the quantitative study by Snorradóttir et al. (2013), the association of social support with psychological distress was measured according to its different sources (friends and family, supervisors, and co-workers), it only assessed whether employees felt that social support was available to them and did not distinguish between different types of social support. This qualitative study showed that some types of social support might be insufficient for coping with challenges in a changing work environment. Future quantitative assessments of social support during organizational changes could therefore profit from distinguishing between emotional and instrumental support in the workplace, in addition to raising questions about support from supervisors or co-workers.

As pointed out above, many of the previous studies on social support during organizational changes have focused on a lack of social support (Niedhammer et al., 2006; Petterson et al., 2005; Vahtera et al., 2000) or reported on how social networks within the workplace are disrupted and social cohesion is lost following downsizing (Campbell \& Pepper, 2006; Koeber, 2002; Shah, 2000). This study shows similar findings, but only in departments where the psychosocial work environment was poor prior to the changes or for employees transferred to a new department. Most of the employees in this study experience increased social cohesion during major organizational changes. This may underline what an extreme case of organizational change this was, as employees were not only confronted with layoffs and dramatic reorganization, but also with resentment and blame from society as a whole. The descriptions of increased social cohesion reflect other findings for societal groups or communities that have undergone major traumas (Alexander, 2004). Such groups have been found to form strong bonds characterized by supportive networks and increased cohesion among individuals. It is important for the traumatized group and individuals to overcome the tragic event (Friedkin, 2004). The extreme nature of this particular case, involving organizational changes, personal attacks, and perceptions of being marginalized in society, may explain why social cohesion increased for the participants while in other studies, less cohesion and more conflicts are found to be characteristic of organizational changes.

\subsection{Conclusion}

This study points to a complex picture of the presence and nature of social support during organizational changes. It showed that during major organizational changes when new stressors are presented, employees can benefit from social support. The study demonstrated that to meet the stressors that arise in such a work environment, both emotional and instrumental support need to be considered and enhanced or implemented. The role of supervisors in leading the employees during organizational changes was found to be very important; these supervisors can make a difference in enhancing effective social support within the group of employees. Future studies on social support during organizational changes could profit from a more detailed investigation of social support, thereby contributing to the identification of more ways of preserving and strengthening social support under difficult conditions.

\section{References}

Alexander, J. C. (2004). Towards a theory of cultural trauma. In R. Eyerman, J. C. Alexander, B. Giesen, N. J. Smelser, \& P. Sztompka (Eds.), Cultural trauma and collective identity (pp. 1-30). Berkeley: University of California Press. http://dx.doi.org/10.1525/california/9780520235946.003.0001

Arnetz, B. B. (2005). Subjective indicators as a gauge for improving organizational well-being. An attempt to apply the cognitive activation theory to organizations. Psychoneuroendocrinology, 30(10), 1022-1026. http://dx.doi.org/10.1016/j.psyneuen.2005.03.016

Braun, V., \& Clarke, V. (2013). Successful qualitative reserach: A practical guide for beginners. Los Angeles: Sage. 
Campbell, R., \& Pepper, L. (2006). Downsizing and social cohesion: The case of downsizing survivors. New Solutions: A Journal of Environmental and Occupational Health Policy, 16(4), 373-393. http://dx.doi.org/10.2190/H922-8H7J-T3R1-1314

Durkheim, E. (1972). Emile Durkheim, selected writings. New York: Cambridge University Press.

Ferrie, J. E., Westerlund, H., Virtanen, M., Vahtera, J., \& Kivimki, M. (2008). Flexible labor markets and employee health. Scandinavian Journal of Work, Environment and Health, Supplement(6), 98-110.

Friedkin, N. E. (2004). Social cohesion. Annual Review of Sociology, 30, 409-425. http://dx.doi.org/10.1146/annurev.soc.30.012703.110625

Hertting, A., Nilsson, K., Theorell, T., \& Larsson, U. S. (2004). Downsizing and reorganization: Demands, challenges and ambiguity for registered nurses. Journal of Advanced Nursing, 45(2), 145-154. http://dx.doi.org/10.1046/j.1365-2648.2003.02876.x

House, J. (1981). Work stress and social support. Reading: Addison-Wesley.

Kivimaki, M., Vahtera, J., Pentti, J., \& Ferrie, J. E. (2000). Factors underlying the effect of organisational downsizing on health of employees: longitudinal cohort study. British Medical Journal, 320(7240), 971-975.

Koeber, C. (2002). Corporate restructuring, downsizing, and the middle class: The process and meaning of worker displacement in the "new" economy. Qualitative Sociology, 25(2), 217-246.

Lavoie-Tremblay, M., Bonin, J. P., Lesage, A. D., Bonneville-Roussy, A., Lavigne, G. L., \& Laroche, D. (2010). Contribution of the psychosocial work environment to psychological distress among health care professionals before and during a major organizational change. Health Care Manager, 29(4), 293-304. http://dx.doi.org/10.1097/HCM.0b013e3181fa022e

Matthíasson, T. (2008). Spinning out of control: Iceland in crisis. Nordic Journal of Political Economy, 34(3), 1-19. Retrieved from http://www.nopecjournal.org/NOPEC_2008_a03.pdf

McGuire, G. M. (2007). Intimate work: A typology of the social support that workers provide to their network members. Work and Occupations, 34(2), 125-147. http://dx.doi.org/10.1177/0730888406297313

Ng, T. W. H., \& Sorensen, K. L. (2008). Toward a further understanding of the relationships between perceptions of support and work attitudes: A meta-analysis. Group and Organization Management, 33(3), 243-268. http://dx.doi.org/10.1177/1059601107313307

Niedhammer, I., Chastang, J. F., David, S., Barouhiel, L., \& Barrandon, G. (2006). Psychosocial work environment and mental health: Job-strain and effort-reward imbalance models in a context of major organizational changes. International Journal of Occupational and Environmental Health, 12(2), 111-119. http://dx.doi.org/10.1179/oeh.2006.12.2.111

Petterson, I. L., Hertting, A., Hagberg, L., \& Theorell, T. (2005). Are trends in work and health conditions interrelated? A study of Swedish hospital employees in the 1990s. Journal Occupational Health Psycholology, 10(2), 110-120. http://dx.doi.org/10.1037/1076-8998.10.2.110

Quinlan, M., \& Bohle, P. (2009). Overstretched and unreciprocated commitment: Reviewing research on the occupational health and safety effects of downsizing and job insecurity. International Journal of Health Services, 39(1), 1-44. http://dx.doi.org/10.2190/HS.39.1.a

Shah, P. P. (2000). Network destruction: The structural implications of downsizing. Academy of Management Journal, 43(1), 101-112. http://dx.doi.org/10.2307/1556389

Snorradóttir, Á., Tómasson, K., Vilhjálmsson, R., \& Rafnsdóttir, G. L. (2015). The health and well-being of bankers following downsizing: a comparison of stayers and leavers. Work, Employment \& Society, 29(5), 738-756. http://dx.doi.org/10.1177/0950017014563106

Snorradóttir, Á., Vilhjálmsson, R., Rafnsdóttir, G. L., \& Tómasson, K. (2013). Financial crisis and collapsed banks: Psychological distress and work related factors among surviving employees-A nation-wide study. American Journal of Industrial Medicine, 56(9), 1095-1106. http://dx.doi.org/10.1002/ajim.22210

Stensaker, I. G., \& Langley, A. (2010). Change Management Choices and Trajectories in a Multidivisional Firm. British Journal of Management, 21(1), 7-27. http://dx.doi.org/10.1111/j.1467-8551.2009.00657.x 
Svensen, E., Neset, G., \& Eriksen, H. R. (2007). Factors associated with a positive attitude towards change among employees during the early phase of a downsizing process. Scandinavian Journal of Psychology, 48(2), 153-159. http://dx.doi.org/10.1111/j.1467-9450.2007.00577.x

Thórisdóttir, H., \& Karólínudóttir, K. E. (2014). The boom and the bust: Can theories from social psychology and related disciplines account for one country's economic crisis? Analyses of Social Issues and Public Policy, 14(1), 281-310. http://dx.doi.org/10.1111/asap.12051

Uchino, B. N., Cacioppo, J. T., \& Kiecolt-Glaser, J. K. (1996). The relationship between social support and physiological processes: A review with emphasis on underlying mechanisms and implications for health. Psychological Bulletin, 119(3), 488-531. http://dx.doi.org/10.1037/0033-2909.119.3.488

Vahtera, J., Kivimäki, M., Pentti, J., \& Theorell, T. (2000). Effect of change in the psychosocial work environment on sickness absence: A seven year follow up of initially healthy employees. Journal of Epidemiology and Community Health, 54(7), 484-493. http://dx.doi.org/10.1136/jech.54.7.484

\section{Note}

Note 1 According to the Confederation of Icelandic Bank and finance Employees, almost all employees working in financial institutions are members of the union.

\section{Copyrights}

Copyright for this article is retained by the author(s), with first publication rights granted to the journal.

This is an open-access article distributed under the terms and conditions of the Creative Commons Attribution license (http://creativecommons.org/licenses/by/3.0/). 